\title{
TRANSDISCIPLINARY IN MODERN ECONOMIC EDUCATION: APPROACHES AND EVOLUTION
}

\section{Oleksiy Stupnytskyy ${ }^{1}$}

DOI: https://doi.org/10.30525/978-9934-588-53-2-12

Abstract. The article deals with the transdisciplinary approach as an interdependent system of knowledge integration, expressed in research and teaching the economic disciplines. The problems of organization and development of transdisciplinary research are considered to be modern paradigms for development of science in the most promising and soughtafter areas of the society. It is noted that transdisciplinary research can be organized in different ways as a tool to search for new scientific knowledge. Modem education system is actively looking for a synthesis methodology of scientific disciplines and interdisciplinary knowledge. This problem is solved in two ways: on the one hand, according to the transdisciplinary economical, environmental and social components play the role of natural elements of complex multifactor model. On the other hand, modern experts in education set their hopes mostly on transdisciplinary synthesis as the possibility of combination and deconstruction of different fragments of social-humanitarian knowledge. Based on an transdisciplinary approach the scientific base and system of education as a complex of fundamental and taxonomic disciplines are considered. At the same time the transdisciplinary connections with the focus on the effectiveness of training are considered. It contains the consistency of educational programmes, determined by didactic goals and content with the competence approach which allow transferring knowledge, skills and abilities from one sphere of science, education and professional activity to another. The organization of synthesis of transdisciplinary knowledge on the basis of principles of scientific rigor and validity which contributes to finding a solution to the problem of effective management of educational process is justified. Both significant advantages and problems arising from the use of the

\footnotetext{
${ }^{1}$ Candidate of Economic Sciences,

Professor at Department of International Business,

Institute of International Relations Taras Shevchenko National University of Kyiv, Ukraine

(C) Oleksiy Stupnytskyy
} 
transdisciplinary approach in teaching economic courses are noted. The project approach is considered, which is based on the construction of the 'architectural' style of student thinking, a communication system for free dissemination of project culture, integration of economic education, innovation and research. The author draws attention to the fact that, on the one hand, in the Ukrainian state policy in the field of education and practice, no approach to the organization of transdisciplinary research has so far been systematically reflected and is not described in the programme documents of the country's scientific and technological development. On the other hand, the existing tools to support education and science to one degree or another comply with the principle of science management "from top to bottom" and are focused on educational research in accordance with pre-defined topics and established priorities.

\section{Introduction}

The current integrative processes in education are discussed in various theoretical and applied studies where their place and significance is revealed due to the relationship between the individual subjects of the educational process (the integrity and consistency of the disciplines of the humanitarian and natural-science cycles). At the same time, most methods of teaching economic disciplines still focus on memorizing material and transferring knowledge without due attention to modern challenges of new emerging ecosystems. If scientific approaches are classified according to the criterion of completeness of knowledge of the surrounding world, then all approaches can be reduced to four main types: disciplinary, interdisciplinary (allows direct transfer of research methods from one scientific discipline to another), multidisciplinary (using a generalized picture of the subject of research, in relation to which all of its disciplinary pictures appear as its parts) and the transdisciplinary system approach as a meta-methodology. It is the analysis of the latter in the context of teaching economic disciplines that is relevant today, since it combines training and practical application of knowledge in the face of inconsistencies (contradictions) between new empirical facts and old theoretical methods for explaining them by educational institutions designed to ensure perception, accumulation, distribution and use of knowledge and scientific information. 


\section{Genesis of the Transdisciplinary Concept in Education}

The growth of globalization of the world economy has contributed to the emergence of the new term 'transdisciplinarity' which characterizes the corresponding direction, which is already quite deserving of its own qualification as a science (for example, Science \& Technology Studies, STS). The concept of transdisciplinarity and its first definition as distribution of interdisciplinary relations within a global system without strict boundaries between disciplines was proposed by the Swiss psychologist J. Piaget, the creator of the theory of cognitive development, back in 1970. In particular, he predicted that after the stage of interdisciplinary research, one a higher stage - a transdisciplinary one - should be expected; it will not be limited to interdisciplinary relations, but will place these relations within the global system without strict boundaries between disciplines [1]. In the first sense, transdisciplinarity is understood as a 'declaration' proclaiming equal rights of famous and little-known scientists, large and small scientific disciplines, cultures and religions in the study of the world (in this meaning, transdisciplinarity plays the role of a 'safeguard' for any separate point of view [2]). In the second meaning, transdisciplinarity is interpreted as a high level of education, versatility, and universality of knowledge of a particular person (an individual with encyclopedic knowledge) [3]. In the third meaning, transdisciplinarity is interpreted as a "rule of exploration of the surrounding world" (a model of comprehensive knowledge at the physical, social and mental levels, as local in the global [4]. In the fourth meaning, transdisciplinarity is used as the "principle of organization of scientific knowledge" involving interaction of many areas of scientific research in solving complex problems of human development, nature and society.

The main trends of world scientific and technological progress are accelerated development of convergent sciences and formation on this basis of convergent technologies (for example, NBIC technologies), interdisciplinary research and technology complexes of the mega-science class in major research centres, as well as the growing importance of the transdisciplinary approach in scientific research. The UNESCO document "World Declaration on Higher Education for the 21st Century: Approaches and Practical Measures" reflects the relevance of transdisciplinarity for educational currricula, as well as its importance from the point of view of a long-term orientation towards the adequacy of higher education to expectations of 
the society. In particular, it says that multidisciplinary and interdisciplinary approaches do not effectively protect against the ongoing fragmentation of knowledge, because, through simple comparison or assembly of disciplinary approaches, they do not reach that depth of 'integration' of the fundamental unity lying in basis of all forms of knowledge. Their conceptual and methodological tools should be rethought. Transdisciplinarity was originally designed as a meta-methodology, therefore, the transdisciplinary approach takes those different techniques of various disciplines, only to 'transform' and 'surpass' them [5]. In addition, articles 5 and 6 contain recommendations to encourage the transdisciplinarity of educational curricula and to train future specialists in using the transdisciplinary approach to solve complex problems of the nature and society $[6 ; 7]$.

The process of development of economic science is accompanied by alternating stages of differentiation (the concept of monodisciplinarity - the growing 'tree' of thematic knowledge) and integration of scientific disciplines (the concept of integrity - formation of interdisciplinary connections and stable multidisciplinary clusters). The indicated alternation corresponds to the dominance of approaches to cognition based on different worldview principles, and the problem of integrating economic disciplines gives rise to interconnection of subjective interpretations of monodisciplinary knowledge in the process of interdisciplinary research. According to T.Remadier, interdisciplinarity differs from multidisciplinarity in that it constructs a common model for the disciplines involved based on the dialogue between them [8]. Biophysics, biochemistry, biogeochemistry, mathematical economics - all these are branches of science that arose in the 20th century as a result of multidisciplinary research. However, in the twenty-first century solving global problems (climate change, increasing agricultural production, sustainable economic development, etc.), when issues of economics, ecology and sociology should be addressed simultaneously, an interdisciplinary approach to organizing research is often not applicable for a holistic description of the problem being studied [9].

According to the results of research by the Belgian scientist A. Judge [10], in modern science there are four types of transdisciplinarity. The most general view is transdisciplinarity-1 which is based on a formal relationship between understandings of individual disciplines and provides formation of logical meta-frames through which their knowledge can be 
integrated at a higher level of abstraction (as opposed to interdisciplinarity). Especially often, it is used in development of various expert systems and work of expert groups. Transdisciplinarity- 2 has a closer internal connection with the researchers' personal experience, including meditation; transdisciplinarity-3 is associated with the use of fundamental cognitive meaning, as well as illustrative metaphors and figurative language; transdisciplinarity-4 is an independent scientific field with its own approach and language, measurement units and models of reality, a method of analyzing information and analyzing the risk of decisions made. It is the latter that makes it possible to carry out a general scientific classification and systematization of disciplinary knowledge using general metaphors that have fundamental cognitive significance.

According to many scholars who intend to search for new knowledge by combining efforts within the framework of several separate disciplines, a common approach has now been developed to separation of multidisciplinarity, interdisciplinarity and transdisciplinarity [11]. For example, R. Lawrence defines interdisciplinarity as maintaining disciplinary boundaries; multidisciplinarity as a combination of methodological and conceptual tools of various fields of science; transdisciplinarity as a way of synthesizing the resources of the disciplinary and non-disciplinary spheres (special cognitive model) [12]. Currently, there are several approaches to understanding the phenomenon of transdisciplinarity. B. Nicolescu's (France) approach to transdisciplinarity implies its complementarity of multidisciplinary and interdisciplinary approaches to research, each form of knowledge and, accordingly, the need for a common methodology [13]. The approach of K. Paul and G. Hadorn (Switzerland) is based on the fact that the need for a transdisciplinary approach arises in the analysis of complex economic and social problems whose solution can have a significant impact on society (development of reflectivity through recursion (France) every effort in a certain phase of the study becomes an 'experiment') [14]. There is an approach based on the use of transdisciplinarity as a resource for the synergy of the prospects of expert (academic) and everyday (unprofessional) types of knowledge to solve problems. Within the framework of this approach, the principles of transdisciplinary research design and their methodology are applied, based on the identification of interaction mechanisms between the scientific community, industry and 
the business sector ('sustainable development + risks of technological modernization'). There are approaches presented by M.Gibbons and P.Scott (the theoretical concept of the 'second type of knowledge production in which transdisciplinarity is key), as well as J. Ravets and S. Funtovich (the theoretical concept of 'postnormal science' fixing the transdisciplinary parameters of the new modern knowledge). In any case, researchers of this phenomenon agree that the transcisciplinary approach is the highest form of an integrated approach to scientific knowledge based on the interaction of not only scientists and researchers, but also representatives of the unscientific community.

The loss by economic disciplines and disciplinary knowledge of their identification features (and sometimes the meaning of their autonomous existence) is based on changes in worldview and truth criteria when describing an object as part of a single ordered environment that can ensure their equivalent participation in the synthesis process, for example, with natural sciences and exact disciplines. Therefore, the knowledge gained by individual economic disciplines should be interpreted from the position of transdisciplinarity, and their reliability and validity is determined by: a) qualified transdisciplinary groups of researchers, b) market competitiveness, c) practical utility, d) value for money [15]. In fact, the assessment tools for the system of transdisciplinary integration should be formed based on two main aspects: first, formation of a fund of assessment tools from the perspective of transdisciplinary integration; second, the ratio of students' professional and general cultural competencies, which is the basis of transdisciplinary integration.

\section{Features of the Modern Stage of Transdisciplinary Research in the Field of Education}

Accelerated formation of Industry 4.0 under the influence of information and communication technologies (ICT) is a significant incentive for the development of transdisciplinary research today. The transformations associated with 'exploding' ICTs are changing the nature of relations in the field of education in connection with the emergence of social network communities and artificial intelligence technologies (AIT), and form new skills in economic education. The latter is influenced by the new architecture of online education in the MOOC format (massive open online course), 
virtualization and gamification of educational processes, as well as achievements in cognitive psychology. The task of creating a new transdisciplinary education is to maintain three areas of infrastructure that have the greatest impact on the transformation of economic education: 1) exchange infrastructure: the ICT sector which affects all the processes of creating and transmitting information; 2) production and consumption infrastructure: financial and investment spheres that establish general rules for interaction in the economic system between production and education; 3) corporeality infrastructure: an area that works (in a broad sense) with the body and mind, where the number of solutions to increase productivity and expand behavioural capabilities is growing rapidly. Elements of the virtual interface are reproduced in individual cases when developing simulators and training systems which become the basis for most educational environments (vocational training, social skills training, formation of worldviews, correcting deviant behaviour, etc.). Moreover, visualization as an augmented reality technology allows creating highly specialized economic spaces and educational quests for joint creativity, while transforming the process of developing new products, projects and digital environments.

A significant component of the development of transdisciplinary relations is the increasing importance of additional services, such as consultations and certification of students by employers, employment of successful students by leading world companies that are partners of universities, etc. Content projects of leading world universities are currently being implemented in this direction, e.g. Coursera (led by Stanford University and bringing together more than 100 universities), Edx (initiated by Harvard University and MIT for 50 leading universities and organizations), which are implemented by the best international professionals in relevant subjects. It is also assumed that in the medium term, the online education market will be centralized by the services of mega providers and 10-15 large alliances will be created around the world's leading suppliers, claiming the entire global (intercountry) education market. They will take over, firstly, the bulk of online students, as well as a significant proportion of students, grouped around the online projects of world leaders in the field of offline education, providing basic content; secondly, the process of forming standards, principles and values of online students which are associated with a very narrow group of suppliers. 
The first and main challenge to interdisciplinarity and the incentive for development of transdisciplinarity is the 'response reduction' of the existing cognitive paradigms (especially when modelling complex systems and creating a new language for describing complex systems). We are talking about the transition from analytical to algorithmic models, because, unlike classical physics which describes the mathematical law expressed in differential equations, complex economic systems are associated with agents that interact by far from simple rules. This makes significant changes to the language for describing complex objects and measured economic parameters, description of the algorithms of the components of a complex system, and the final calculation model. In fact, digital models and virtual worlds are turning into new laboratories that contribute, firstly, to development of 'reusable' simulations for a variety of economic experiments - from in vitro (availability of special equipment and drugs) to in silico (only computational models); secondly, to creation of new algorithms for processing large amounts of data as part of a 'dialogue' between data collection systems and analytical systems.

World trends in development of modern economic science pay considerable attention to the use of theories and concepts that are transdisciplinary in nature as basic methodological approaches. In developed OECD countries (especially in the USA and EU countries), it has already been realized that new breakthroughs in science and education are in most cases associated with transdisciplinary research. There are institutions aiming at stimulating transdisciplinary cooperation. In the USA it is the National Science Foundation (NSF), and in Europe it is the Horizon 2020 Programme for supporting transdisciplinary research. Cooperation in the field of transdisciplinarity has become a new trend in the world of scientific research. Currently, the NSF has focused on programmes involving transdisciplinary interaction (up to $35 \%$ of the total number of programmes), has developed common priorities, effectively distributed powers, and eliminated duplication of functions. An example is the National Nanotechnology Initiative programme, which brings together all federal departments in conducting research in the field of nanotechnology. As a result of their cooperation, the synergistic effect of their interaction is manifested in the successful development of individual innovative projects of the Initiative [16]. In 2013, under the auspices of the American Academy of Science and Culture, the ARISE-2 (Advancing 
Research in Science and Engineering) Report was published in the United States. Its main goals are to carry out "transition from interdisciplinarity to transdisciplinarity" in American science, since interdisciplinarity implies simple "borrowing" of techniques and methods from other fields of science, while transdisciplinarity implies a "functional synthesis of methodologies", and creation of completely new research concepts on their basis [17].

Today, there are several schools of transdisciplinarity established within the framework of large research centres (The Academy of Transdisciplinary Learning \& Advance Studies, Santa Fe Institute, Network for Transdisciplinary in sciences and humanities, International Center for Transdisciplinary Research), as well as specialized educational and research organizations which are examples of convergence of economic and socially demanded knowledge (CIRET, France; ATLAS, European Union; SCITS, USA). An example of development of the concept of transdisciplinarity is the French school of transdisciplinarity which operates in the direction of searching for formal relationship of individual disciplines, prefers close internal connections with the personal experience of the researcher, as well as the use of general metaphors that are of fundamental cognitive value. For example, Paris CRI (Centre for Research and Interdisciplinarity), founded in 2005, is engaged in introduction of modern technologies in education, project training and implementation of the results of collective intelligence. CRI uses modern teaching methods and strategies, allowing students to take the initiative and develop their own projects, which are supervised by teachers, research centres, private companies and foundations. These days, CRI, in cooperation with the universities of Paris Descartes and Paris Diderot, has started undergraduate and graduate programmes (AIRE: Interdisciplinary and innovative approaches to research and teaching, field Technologies in Education), as well as laboratories of the French Institute of Health and Medical Research (INSERM). In addition to the main academic sylabus, CRI has various associations created by students, such as a popular science platform WAX Science (What About Xperiencing Science), the les Savanturiers pedagogical center, the HelloTomorrow startup summit, le Gamilier educational games club, etc. [18].

Therefore, transdisciplinarity is by far the most demanded and at the same time the most difficult form of scientific integration. Thus, the Charter of Transdisciplinarity has formulated three important aspects 
of this phenomenon. Firstly, the existence of different levels of reality assuming different types of logic is recognized as an integral feature of the transdisciplinary approach. Secondly, transdisciplinarity complements the interdisciplinary approach looking for new forms of interaction between disciplines (their unity and that which lies beyond them). Thirdly, transdisciplinary vision is based on an open dialogue of the exact and human sciences, as well as a dialogue of art and spiritual experience [19]. If the interdisciplinary approach to teaching economic disciplines is characterized by minimal integration, it implies studying an object or phenomenon simultaneously and from different sides by several scientific disciplines, while each discipline preserves its own methodology and theoretical assumptions, without modifying or supplementing them, transdisciplinarity takes a different approach. Transdisciplinarity as a concept, firstly, crosses disciplinary boundaries and means integration of various forms and methods of studying economic problems (in the narrow sense) and the unity of knowledge outside specific disciplines (in the broad sense). Secondly, it not only enriches economic knowledge, but also allows you to develop macro-object and macro-process management technologies (including the educational process itself), methods and technical means of obtaining and processing information (primarily new generation computers, artificial intelligence technologies, etc.).

The advent of NeuroWeb (the next generation of the Internet, based on neural interfaces) for direct transfer of values, images and sensations can fundamentally change the transdisciplinarity concept and approaches to economic training, including the speed of learning, methods of transferring knowledge and skills, as well as new opportunities for shared and mutual learning. And although this, in a certain sense, will complete the development of the current cycle of classical education, it is impossible to go to the 'pedagogical/educational Internet' without assimilating the practice of 'network pedagogy/teaching/education' which is now actively developing in online education. The content of economic training will focus not on publicly transmitting accessible information and practicing routine exercises, but on developing a set of general skills related to creative thinking, supporting the psychophysical 'shape', values, and self-education will be organized 'horizontally', mainly through mutual exchange of economic knowledge. This means that the system of economic education should pre- 
pare students for new working conditions based on a horizontally flexible organization and a high level of uncertainty, joint study of subjects unfamiliar to both teachers and students and therefore require creative experiments, teamwork and knowledge sharing.

\section{Project-based Learning as Part of a New Transdisciplinary Educational Paradigm}

Transdisciplinary communication in teaching economic disciplines involves a multi-level approach based on the concept that educational and professional activities are an adequate basis for integrative knowledge synthesis, a reliable and effective means of ensuring continuity in formation of universal competencies. On the one hand, it is cognitive skills (generalization, comparison, contrasting, abstraction and concretization, etc.), integrative forms of learning, their active and interactive methods and technologies (business games, simulation games and exercises, case method, project-based learning technology, discussions and brainstorming) that gradually develop into relevant professionally significant competencies. On the other hand, intra-disciplinary communication implemented at the level of fulfilling problem tasks, resolving problem situations, and student project activities is no less important. This contributes to development of a student's personality, freely and consciously oriented in a complex space of economic phenomena and processes, capable of self-actualisation and selfrealisation in a variety of socio-economic relations and interactions.

Project thinking, as an innovative and creative type of thinking [20], has a problem-oriented nature and involves implementation of an organized set of activities that are closely related to each other, but dispersed in time and space. At the same time, a future economist graduate should be able to create and model a multi-factorial space for people to interact in the process of achieving their desired goals, on the one hand, and be able to perceive the project situation and see the prospects for its development in interaction of various processes forming its body, on the other hand. It is important to instill in him the main paradigm of project activity which includes identifying the project design in accordance with the predictive trend, market interaction environment, coordination of different approaches, methodological strategies, technologies and resources, and its organizational and managerial component (group formation and time management). And 
since the emphasis is gradually shifting from the product to the goal and economic environment of designing, the social and humanitarian trend in development of project thinking and activity is dominant. A specialist in the field of economics should possess fundamentally new competencies - the pragmatic and developmental aspects of design require him to take on ever greater responsibility, to be able to predict socio-economic consequences, to minimize financial risks associated with the implementation of the project, and to change the approach to the design process itself.

Implementation of the ISO 9000 quality management system presupposes a project approach that allows these systems to be implemented most effectively, since it involves all levels of the educational process and all its participants at the university, contributing to project thinking formation as an important component of the subject's personality position. The multifunctional project method is organically combined with a cooperative learning approach to economic training and is associated with new principles of personality-oriented education, an individual approach and subjectivity directly associated with their application experience in practical activities [21]. Since the project approach is based on integration of education, innovation and economic and managerial activities, it contributes to development of transdisciplinary competencies in the field of leadership, construction of an 'architectural' style of thinking and an established communication system for free dissemination of project culture. For economic specialties, it is especially relevant because it is conditioned by the increasing employers' requirements to the level of employees' qualification, their professional competence, creative skills, and their ability to define market mechanisms and to apply them in professional practice. The degree of practical orientation of the project approach is determined by different levels of thinking (visual-effective, visual-figurative, verballogical), however, the effective business decision-making is based on productive professional project-management thinking.

The nature of project imagination (in many ways akin to creative) combines fantasy with the ability to imagine a design object against several business contexts at once, to compose its integral context image based on certain characteristics (laterality, criticality, creativity, reflexivity, and problematicity). That is, the economic 'passport' of project thinking needs: a) generating non-competing ideas in a brainstorming mode; b) using the 
incoming information not as self-worth, but as a means of obtaining an optimal result; c) alienation from authoritative opinions, d) self-criticism in comparison and choice of the most appropriate and productive options from the existing components; e) search onset; e) ability to generate ideas; g) search for innovative approaches. The most important functions of project thinking may include:

- search-heuristic (advance of new problems);

- indicative-regulatory (development of goals and principles of project activities, determination of focus and sustainability of actions);

- selective assessment (development of criteria and indicators for evaluating project products);

- prognostic (leading vision of the design situation and difficulties / contradictions that may arise in project activities);

- structurally transforming (correction of one's own actions in the project and improvement of the process of its design);

- integrating (generalization, synthesis of knowledge about the design object from different areas, reaching a new level of understanding of practical problems).

As the problems are complex, unclearly defined and poorly structured, project thinking includes processes of experimentation, information visualization and modelling and it is a long continuous activity. It is far from two-day corporate sessions on the use of the 'Strategy - Product - Service Business' planning model, after which it remains only to implement the plan.

One of the unresolved problems of organising students' work within the framework of transdisciplinary projects in the educational process is the criteria for evaluating their results, which makes it difficult to use projects on a regular basis and makes them only an auxiliary means of enhancing students' learning and independent work. Under the conditions of ICT and AIT development, the main goal of assessing student knowledge is changing: the tendency to shorten the 'assessment cycle' leads to a transition to the 'economy' of merit and 'reputation capital' as universal systems for assessing the achievements of each student. Whether it is in game dynamics, within quest framework and achievement logic with built-in augmented reality, a transition from a hierarchical assessment system to a comprehensive one based on 'development zones' and 'skill profiles' is taking place. As an analysis of the teaching of economic disciplines testifies, 
the way the topics for transdisciplinary projects are formulated does not often allow students to fully reveal their creative potential in their project implementation. The practice of working with students of the International Business at the Institute of International Relations of Taras Shevchenko Kyiv National University (Ukraine) shows that although knowledge of the criteria for evaluating interdisciplinary projects serves as an indicative basis for independent work on a project, it does not yet prepare the students for achieving transdisciplinarity status in their research. It is connected, first of all, with the fact that a transdisciplinary project is a rather simplified model of a complex system fixing connections between different subject areas and, accordingly, different faces of the same object; secondly, it implies the complexity of psychological idea of the genesis of transdisciplinary activity. Therefore, development of the project by a student-economist should correspond to: 1) the potential of subject areas in its solution (the principle of large-scale correspondence of the problem and subject areas); 2) preservation of the original context of concepts (semantic homogeneity); 3) enlargement dynamics of cause-effect relationships and similar ties (the principle of increasing mediation). The role of organizing 'open type' project activities is growing, when students formulate the topic of a transdisciplinary project on their own, depending on the importance of current micro- and macroeconomic problems and global economic challenges.

Formation of search skills, selection of alternative solutions, and stimulation of innovative activities are based on practical skills in working with economic information, which contributes to clarity in formulation of goals, objectives, and hypotheses and development of effective algorithms for practical activities of economics students, and makes it possible to approach solving problems from the perspective of many areas of knowledge in the field of management, finance, auditing, consulting, sales, marketing, etc. [22]. The transdisciplinary approach involves acquiring IT skills within various platforms and knowledge of the latest technologies used by a fairly wide range of professions. For economic specialties, we are talking primarily about social informatics - a transdisciplinary approach that studies socio-economic contexts of creation and use of ICT, its rapidly growing application potential in the context of emergence of new forms of labour and employment organization within both business environment and society in general. Consequently, the global system of transdisciplinary education 
'road map' can be summarized as follows: firstly, its contours are becoming more obvious and they are mainly concentrated in the United States thanks to leadership in ICT and AIT development. Secondly, through virtualization of training, gamification and AIT in the framework of collective practice, over-individualised education (it is accessible for students and has market (including employers) demand) contributes to creation of global platforms for preservation of knowledge in real time. Thirdly, wide dissemination of global education standards in old and new areas, thanks to the educational franchise systems of world leaders in the field of university and business education, initiate an increasingly intensive joint projects in developing countries. Fourth, the balance of teachers' employment shifting in the direction of research and development contributes to the increasing role of transnational research teams, which leads to global unification of university rating tables and new standards of educational technologies.

\section{Ukraine is Still at the Stage of Interdisciplinarity}

Although universities still serve to reproduce a specific model of social stratification, global shifts in socio-economic structures are determining the new meaning of educational projects with a broad spatial orientation and formation of new generation $\mathrm{Z}$ elites. Each university will choose a suiting survival strategy, but it should be connected with the search for unique quality in the context of digital education. Otherwise, inertia or resistance to the development of new practices is a suicidal strategy, fraught at best with the illusion of temporary security, and at worst - with accelerated loss of competitive advantage in the educational sphere.

As for Ukraine, according to a World Bank study on global changes in the global labour market, in 2018 it took the 50th place in the ranking among 157 countries in the Human Capital Index ( 0.65 points) (ahead of countries such as Turkey, Georgia and Romania) which was calculated based on the level of development of education and health care in the country. The value of human capital in the rating ranged from 0.8 to 0.88 points, and a country in which a newborn is provided with an ideal level of education and health care received 1 point [23]. However, although Ukraine is ahead of countries with a comparable level of per capita income in terms of education, Global Human Capital rankings indicate that capitalization of the human resource is still low. That is, it 
ranks fifth in the world in terms of the volume of human capital, but only 36th in terms of the actual use of skills in labour activity and inclusion of workforce in continuous education systems. According to a particularly important indicator for economic growth as the availability of skilled workers, Ukraine is in 35th position [24]. Today's Ukrainian continuous education programmes (essential for substantial increase in labour productivity) cover only about $13 \%$ of the workforce, with an average of $40 \%$ in the EU countries, and $66 \%$ in Sweden [25]. The paradox of the current situation in Ukraine is that the level of education is increasing, but labour productivity in the country is practically not growing. In high-income OECD countries, $70 \%$ of the national wealth is made up of human capital monetized in intellectual services, while in Ukraine it is approximately $46 \%$, which is slightly higher than in poor countries, and research and development funding per student is 7 times as low as in universities in OECD countries [26].

Unfortunately, Ukraine has no attractive business environment for technological entrepreneurship (effective mechanisms for venture capital, infrastructure for technology parks and business incubators, legislative protection of property, including intellectual property). Platforms for interaction of teachers, programmers and businessmen through public-private partnerships are being created slowly (not to mention tax breaks and financial support generally accepted in the leading OECD countries). Based on the triumvirate that a government should possess when introducing new education - educational, entrepreneurial and programmer culture, perhaps, Ukraine possesses only the first one to a sufficient degree. Since economic education is a product, the only way to determine its quality is to evaluate it by other users or market experts. A branding educational trajectory is determined not by ratings of educational institutions (which do not say anything about the quality of individual educational modules or even programmes within these institutions), but by peer-to-peer rating systems in the field of education (primarily on sites that aggregate and catalogue a large number of online educational resources). The current and target competency profile of a student-economist depends on live interaction between a teacher acting as an 'educational navigator' and a student who has genuine professional goals, personal skills and orientation. 
The main task of the institutions regulating the national education system is not to reform the existing educational institutions (adaptation to new goals), but rather to create an environment that allows creating new effective education that meets the level and objective pace of the country's development. That is, the development model of education through creation of new projects is more promising than the model for reorganisation of old projects. We are talking about a mutually beneficial partnership between transnational online educational platforms and national education systems in order to integrate them into national talent training support programmes. At the same time, firstly, the best that regulators can do is not to hinder this natural replacement, but also to make it as productive as possible in the public interest. It should also be taken into account that longer cycles of changing curricula as compared to changing technological cycles are a systemic problem in the education system. Secondly, regulatory bodies should create equal "rules of the game" for introducing the best qualities of existing and new approaches, and make way for a balanced system for their communication (social efficiency while respecting national interests and interests of the end user). Thirdly, any excessive preferences for traditional institutions (including state ones) should be excluded, i.e., equal access rights to key resources for different educational institutions (budget, grants, subsidies, etc.) should be respected. Fourth, as part of promoting national high-tech export support programmes, stimulate the export of educational services (including educational technology solutions). Fifth, support research and development in the field of new forms of education through a system of special state grants to create new educational technologies.

Summarizing the experience of the developed OECD countries, it seems necessary to formulate proposals regarding the support of development of transdisciplinary scientific research by the Ukrainian state in the person of the Ministry of Education and Science of Ukraine.

1) It is necessary to legislatively consolidate the support of transdisciplinary scientific research as a principle of implementation of the national scientific and technical policy, which will become the basis for a systematic approach to measures of developing such studies by the subjects of scientific and educational policy. This will create conditions under which 
transdisciplinary scientific relations can be formed freely from the stage of introducing an interdisciplinary approach into the learning process in higher education to the stage of formation of new transdisciplinary scientific fields.

2) It is necessary to accelerate the transition to implementation of the principle of developing scientific knowledge 'from the bottom up' in the context of providing higher education institutions with grants for the socalled frontier research based on new priorities and promising areas for the development of science. This should be done with the support of university research at the intersection of basic and applied sciences, regardless of the disciplinary boundaries of the research (for example, the EU research programme Horizon 2020).

Ukrainian universities (on the assumption of their transition to project-oriented training in the coming years) should turn into spaces for entrepreneurial experiments, into centres for promoting startups, with separate zones created in their structure. Only in a situation where entrepreneurial skills and thinking are taught along with managing a university's venture portfolio, investing in student startups can become a part of the university's financial model. In other words, universities act as centres of gravity and a meeting place for interested employers and potential employees. In the modern Ukrainian education market, the niche of super-low-cost education is one of the opportunities to realize the advantages of the bottom of the pyramid model - this is an increase in the number of start-ups in education with sufficient vision, system solutions and standards suitable for use in the new transdisciplinary education system. The new term 'transdisciplinary society' implies a structure where general knowledge of individuals and disparate collective knowledge merge into one whole in order to solve a common problem. That is, it consists of specialists from different fields and professions (sometimes having degrees in two or more academic majors) included in creation and application of new knowledge. In the near future, in connection with the intensive development of scientific research in the field of transdisciplinarity and its introduction into the general educational practice of universities, educational science will also develop, and the question of the teaching staff will become one of the most important problems of modern economic education. 


\section{Conclusions}

The symbiosis of modern megatrends of development of the global economy and digital technologies as 'soft power 2.0' in the conditions of Industry 4.0 is redefining the relevance of economic education and the genesis of educational ecosystems. All scientific discoveries and breakthrough technologies in modern society are carried out at the intersection of sciences through study of scientific problems. On the one hand, using the transdisciplinary approach, one can comprehensively study the subject of research from different scientific positions, and integration of knowledge based on transdisciplinary connections makes it possible to create a holistic vision of economic problems or phenomena, and their implementation in a competency-based format takes on special significance for formation of synthetic thinking of future economists. The specified format of education allows realizing the principle of individual readiness to solve a clearly defined list of special economic problems in their professional training. This readiness is represented by the unity of knowledge, skills and know-how of the students. On the other hand, the use of a transdisciplinary methodology allows us to systematically cover all the factors of economic development, create a platform for combining the achievements of science and determine the vector of development of education. The transition from an interdisciplinary to transdisciplinary concept in economic education presupposes a change in the approach to the team-project teaching method and in relation to the very concept of project thinking. Obviously, bringing the stated principles of the transdisciplinary methodology to the level of working methods requires further research. However, consideration of fundamental opportunities allows us to conclude that application of systemic-transdisciplinary principles in economic education will increase their level of explainability, expand the heuristic potential of economic science and, thus, allow the transfer of a number of economic phenomena from unpredictable to predictable.

\section{References:}

1. Piaget J. Theory, Experiments, Discussion / Ed. L. Obukhova, G. Burmenskaya. M.: Gardariki, 2001. (in Russian)

2. 1st World Congress of Transdisciplinarity (1994). Preamble. Convento da Arrábida, Portugal, November 2-6. URL: http://perso.club-internet.fr/nicol/ciret/english/charten.htm

3. Somervill, M. A., \& Rapport, D. J. (Ad.) (2000). Transdisciplinarity: Recreating Integrated Knowledge. Published by EOLSS Publishers Co. Ltd. Oxford, UK. 
4. De Mello, M. (2001). The School of the Future. University of São Paulo, Center for Transdisciplinary Education (CETRANS).

5. UNESCO on the World Conference on Higher Education (1998). Higher Education in the Twenty-First Century: Vision and Action. URL: http://www.unesco.org/ cpp/uk/declarations/world.pdf

6. Transdisciplinarity: Stimulating Synergies, Integrating Knowledge Division of Philosophy and Ethics UNESCO, 1998. URL: http://unesdoc.unesco.org/images/0011/001146/114694eo.pdf

7. McGregor, S. L. T., \& Volckmann, R. (2013). Transversity: Transdisciplinarity in Higher Education. In G. Hampson \& M. Rich-Tolsma (Eds.), Leading Transformative Higher Education, pp. 58-81. Olomouc, Czech Republic: Palacky University Press.

8. Remadier, T. (2004). Transdisciplinarity and its Challenges: The Case of Urban Studies. Futures, (36), 433-434.

9. Tress, G., Tress, B., \& Fry, G. (2006). Publishing Integrative Landscape Research: Analysis of Editorial Policies of Peer-reviewed Journals. Environment Scientific Policy, (9), 466-475.

10. Judge, A. (1994). 1st World Congress of Transdisciplinarity. Conference Paper. Union of International Associations. URL: http://www.uia.org/uiadocs/aadocnd4.htm

11. Stock, P. \& Burton, R. J. F. (2011). Defining Terms for Integrated (MultiInter-Trans-Disciplinary) Sustainability Research. Sustainability, (3), 1090-1094.

12. Lawrence, R. J. (2004). Housing and Health: From Interdisciplinary Principles to Transdisciplinary Research and Practice. Futures, (36)/4, 488-489.

13. Nicolescu, B. The Relationship between Complex Thinking and Transdisciplinarity. URL: http://basarab.nicolescu.perso.sfr.fr/ciret/ARTICLES/ Nicolescu fichiers/MSH15062009.htm\# ftn1

14. Pōhl, C., \& Hirsch, H. G. (2007). Principles for Designing Transdisciplinary. Research-proposed by the Swiss Academies of Arts and Sciences. München.

15. Mobjörk, M. (2010). Consulting versus Participatory Transdisciplinarity: A Refined Classification of Transdisciplinary Research. Futures, (42), 866-873.

16. How Does NSF Support Interdisciplinary Research? URL: https://www.nsf.gov/ od/oia/additional_resources/interdisciplinary_research/support.jsp

17. ARISE $2^{-}$(Advancing Research in Science and Engineering). American Academy of Arts and Sciences, 2013. URL: https://www.amacad.org/multimedia/ $\mathrm{pdfs} /$ publications/researchpapersmonographs/arise2.pdf

18. 21st Century Skills: Evidence of Issues in Definition, Demand and Delivery for Development Contexts. Emerging Issues Report. Education Development Trust, August 2019. URL: https://assets.publishing.service.gov.uk/media/5d71187 ce5274a097c07b985/21st_century.pdf

19. Charter of Transdisciplinarity. First World Congress of Transdisciplinarity, 1994. URL: http://inters.org/Freitas-Morin-Nicolescu-Transdisciplinarity

20. Preparing 21 st Century Students for a Global Society. National Education Association. URL: http://www.nea.org/assets/docs/A-Guide-to-Four-Cs.pdf

21. A Guide to the Project Management Body of Knowledge. An American National StandarD ANSI/PMI 99-001-2008. URL: https://www.works.gov.bh/ 
English/ourstrategy/Project\%20Management/Documents/Other\%20PM\%20 Resources/PMBOKGuideFourthEdition_protected.pdf

22. What should Students Learn for the Age of Artificial Intelligence? Center for Curriculum Redesign, February 12, 2019. URL: http://ncee.org/wp-content/ uploads/2019/03/NCEE-Charles-Fadel.pdf

23. Ukraine Entered the Top 50 countries of the World on the Human Capital Index according to the World Bank. URL: https://ain.ua/en/2018/10/25/top-50countries-of-the-world-on-the-human-capital-index/

24. The Global Human Capital Report 2017. Preparing People for the Future of Work. World Economic Forum 2017. URL: http://www3.weforum.org/docs/WEF_ Global_Human_Capital_Report_2017.pdf

25. Digest of Education Statistics 2018. 54th Edition, National Center for Education Statistics, U.S. Department of Education. URL: https://nces.ed.gov/ pubs2020/2020009.pdf

26. High-Tech Human Capital Report 2019. URL: https://innovationisrael.org.il/en/ sites/default/files/High\%20Tech\%20Human\%20Capital\%20Report $\% 202019 \% 20$ -\%20English_25.02-compressed.pdf 